\title{
Promotion as Contrastive Increase in Expected Fit*
}

\author{
Forthcoming, Philosophical Studies
}

(please cite published version)

\author{
Nathaniel Sharadin (natesharadin@gmail.com) \\ Finnur Dellsén (finnurd@gmail.com)
}

Abstract: What is required for an action to promote the satisfaction of a desire? We reject extant answers and propose an an alternative. Our account differs from competing answers in two ways: first, it is contrastive, in that actions promote the satisfaction of desires only as contrasted with other possible actions. Second, it employs a notion of expected fit between desire and world, defined as the weighted sum of the fit between the desire and the world in all possible outcomes, where each weight is given by the probability of the agent's obtaining the relevant outcome. According to our proposal, then, an action promotes a desire when the expected fit for the desire given that the agent performs the action is greater than the expected fit of the desire given that the agent performs the contrasting action. We highlight this account's attractive features and explain how it improves on its competitors.

Keywords: promotion, desire, rationality, Humeanism, probability

\section{Introduction}

It's possible to satisfy desires. If you want $\$ 100$, and you get $\$ 100$, then your desire is satisfied. It's also possible to promote the satisfaction of desires. If you want $\$ 100$, and you get a ticket to a fair lottery the prize for which is $\$ 100$, then although your desire hasn't ipso facto been satisfied, the satisfaction of your desire has been promoted. According to one version of Humeanism about reasons, agents have reason to perform all and only those actions that promote the satisfaction of their desires. ${ }^{1}$ And even among non-Humeans, it seems clear that at least some reasons, viz. the instrumental ones, involve promoting the satisfaction of desires. ${ }^{2}$ What, precisely, is required for an

\footnotetext{
${ }^{1}$ See, for instance, Schroeder (2007) and Manne (2016). Though they are importantly different, both Schroeder and Manne's brands of Humeanism are put explicitly in terms of promoting agents' desires. See also Hubin (1999).

${ }^{2}$ Examples abound. See, for just two instances, Korsgaard (1996) and Scanlon (2015). As Snedegar (2014) points out, even authors not explicitly interested in instrumental reasons -- or even desires -- seem to appeal to the idea of promotion in stating their views. (Compare Snedegar (2014, pp. 46-7).) Here we
}

* Both authors contributed equally to the paper; we've adopted the convention of alternating the order in which our names appear on published work. 
action to promote the satisfaction of a desire? In this paper, we offer a new account, highlight its attractive features, and explain how it improves on its competitors.

All of the most prominent accounts of promotion appeal to the notion of probability, so we begin (in section 2) by describing two recent probabilistic accounts -- Pure Probabilism and Causal Probabilism. We'll argue that both accounts face serious problems, but that these can be solved by recognizing that promotion is contrastive (in a sense to be explicated). But that's not the end of the story, since even contrastive probabilistic accounts of promotion face a peculiar problem first identified by one of the present authors in previous work (Sharadin (2015)). Sharadin suggests solving this problem with a disjunctive account that introduces the notion of "fit" between desire and world. But we'll argue that Sharadin's prior account, even when modified to take account of the contrastive nature of promotion, is also problematic. In section 4, we describe two related problems with Sharadin's view. This completes the main negative argument of the paper: extant proposals regarding promotion are, we think, unacceptable. In sections 5 and 6, we describe our own account, and explain how it accommodates the virtues of Sharadin's earlier account while elegantly solving its problems. In the penultimate section (section 7) we'll explain how our view's neutrality on the question of what sort of probabilities are at issue is a feature rather than a bug of the view. We conclude by reflecting on where this leaves the debate over promotion.

\section{Probabilism: Pure, Causal, and Contrastive}

\subsection{Pure Probabilism}

One recent proposal is that promoting the satisfaction of a desire -- promoting a desire, for short -- is simply a matter of its satisfaction being more probable given the action that it would otherwise be. According to the most general version of this view:

Pure Probabilism: Agent A's $\varphi$-ing promotes desire D iff pr(satisfaction of $\mathrm{D} \mid \mathrm{A} \varphi s)>\operatorname{pr}($ satisfaction of $\mathrm{D} \mid \mathrm{B})$.

\footnotetext{
won't be concerned with the details of the relationship between promotion and instrumental reasons, or promotion and other possible objects of promotion (such as values, or objectives, or ends); instead, with others in the literature (e.g. Behrends and DiPaolo (2015), Lin (2016)), we'll take there to be some plausible relationship between reasons and promotion and we'll treat the promotion relation as independently interesting. We'll also focus our attention in what follows on promoting desires (rather than, say, ends or values), but nothing important hangs on this focus. For more on the relationship between reasons and promotion, see the discussion in Kolodny (forthcoming) and Maguire (2016).
} 
Where B (for Baseline) is filled in by the specific version of the purely probabilistic view on offer. For instance, Mark Schroeder says that the baseline is the agent performing no action whatsoever. ${ }^{3}$ Stephen Finlay claims the baseline is the agent not performing the action in question (e.g., not- $\varphi$-ing). ${ }^{4}$ D. Justin Coates holds that the baseline comprises whatever facts contribute to the "antecedent intrinsic likelihood" of D's being satisfied.

Pure Probabilism yields intuitively correct results in a wide range of cases. For instance, working for the moment with Schroeder's account of the baseline, we can explain why buying a ticket to the lottery might promote your desire for $\$ 100$. If we suppose that the probability that you'll get $\$ 100$ if you do nothing is quite low (you have no salary, and no one is likely to give you the money, say), that the lottery is fair, and that there will only be 100 tickets sold, then buying a ticket to the lottery would plausibly promote your desire. For instance, if the probability that you'll get $\$ 100$ if you do nothing is .002 , then buying a ticket promotes your desire, since the probability that you'll get $\$ 100$ if you buy a single ticket is .01, and .01>.002.

Similar remarks go for a range of other cases. Intuitively, Pure Probabilism captures something important about the connection between the (instrumental) reasons there are to perform actions and the likelihood that our desires will be satisfied if we perform those actions: when the satisfaction of our desires is more likely given some actions we might perform, i.e., when the actions do what purely probabilistic accounts of promotion say is necessary and sufficient to promote those desires, then we have (at least some) reason to perform those actions.

However, Pure Probabilism faces a range of related counterexamples due to Jeffrey Behrends and Joshua DiPaolo. ${ }^{6}$ The details of the counterexamples depend, in part, on what purely probabilistic account is being targeted. That is, the details of the counterexamples depend on what account of the baseline the relevant purely probabilistic account accepts. So, for instance, switching now to Finlay's account of the baseline as our target, we can construct a counterexample such as:

\footnotetext{
${ }^{3}$ Schroeder (2007, p. 113).

${ }^{4}$ Finlay (2006, p. 8). Finlay's view is complicated in his (2014): there, he offers a probabilistic account of the good for relation rather than the promotion relation. Here, we'll discuss his (2006) view. Thanks to [removed for blind review] for suggesting clarity on this point.

${ }^{5}$ Coates (2014, p. 5). See Sharadin (2015, esp. fn. 21) for some worries regarding the notion of an "antecedent intrinsic likelihood."

${ }^{6}$ C.f. their $(2011,2016)$.
} 
Debbie: Debbie has some desire. There are three buttons in front of her. If she pushes either Button A or Button B, her desire is guaranteed to be fulfilled. If she pushes button $C$, her desire will not be fulfilled. Debbie in fact pushes A. Had she not pushed A, she would have pushed B instead. ${ }^{7}$

According to Finlay's purely probabilistic account of promotion, an action promotes the satisfaction of a desire only if the probability of that desire's being satisfied is greater than the probability that the desire will be satisfied given that the agent does not perform the relevant action. If that's right, then Debbie doesn't promote the satisfaction of her desire even if she does something that directly leads to the satisfaction of her desire, viz. pressing button A.

To see why, note that since Debbie would have pressed B had she not pressed A, the probability that she presses $\mathrm{B}$ given that she does not press $\mathrm{A}$ is 1 . It follows that the probability of satisfying her desire given that she does not press $\mathrm{A}$ is equal to the probability of satisfying her desire given that she presses $\mathrm{B} .{ }^{8}$ But since her desire is equally likely to be satisfied if she presses B as it is if she presses A (i.e., since the probability is 1 in both cases), it follows that the probability of her desire's satisfaction given that she presses A is equal to its probability given that she doesn't press A. So, she can't perform any action such that the probability of her desire's being satisfied would be higher than it is given the baseline of 'not pressing A.' So, on Finlay's view, this means she can't promote her desire by pressing A. Intuitively, however, Debbie can promote her desire by pressing A: after all, pressing A immediately results in her desire's being satisfied! And this is so even if it's also true that pressing $B$ would promote the satisfaction of her desire. If you're not convinced, consider the corresponding reasonable claims about what Debbie has reason to do. Presumably, since pressing A guarantees the satisfaction of her desire, Debbie has (instrumental) reason to press A. But if Finlay's account is correct, then we are barred from saying this: for, since pressing A doesn't promote the satisfaction of Debbie's desire, there's no

\footnotetext{
${ }^{7}$ Behrends and DiPaolo (2011, p. 2). In order for this counterexample to work, the counterfactual statement at the end of the example must be understood as implying that Debbie's probability of pushing B given that she doesn't push A is 1 .

${ }^{8}$ Let $\mathrm{S}_{\mathrm{D}}$ be the proposition that Debbie's desire is satisfied, and let $\mathrm{P}_{\mathrm{A}}$ and $\mathrm{P}_{\mathrm{B}}$ be the propositions that Debbie presses A and $\mathrm{B}$ respectively. Now, it is theorem of the probability calculus that $\operatorname{pr}\left(\mathrm{S}_{\mathrm{D}} \mid \neg \mathrm{P}_{\mathrm{A}}\right)=\operatorname{pr}\left(\mathrm{S}_{\mathrm{D}} \mid \mathrm{P}_{\mathrm{B}}\right) \operatorname{pr}\left(\mathrm{P}_{\mathrm{B}} \mid \neg \mathrm{P}_{\mathrm{A}}\right)+\operatorname{pr}\left(\mathrm{S}_{\mathrm{D}} \mid \neg \mathrm{P}_{\mathrm{B}}\right) \operatorname{pr}\left(\neg \mathrm{P}_{\mathrm{B}} \mid \neg \mathrm{P}_{\mathrm{A}}\right)$.

In Buttons, it is meant to be stipulated that $\operatorname{pr}\left(\mathrm{P}_{\mathrm{B}} \mid \neg \mathrm{P}_{\mathrm{A}}\right)=1$ (see the previous footnote), and thus that $\operatorname{pr}\left(\neg \mathrm{P}_{\mathrm{B}} \mid \neg \mathrm{P}_{\mathrm{A}}\right)=0$. It follows from the theorem that $\operatorname{pr}\left(\mathrm{S}_{\mathrm{D}} \mid \neg \mathrm{P}_{\mathrm{A}}\right)=\operatorname{pr}\left(\mathrm{S}_{\mathrm{D}} \mid \mathrm{P}_{\mathrm{B}}\right)$.
} 
(promotive, instrumental) reason for Debbie to press A.

It might seem as if this counterexample depends on Finlay's idiosyncratic view of what the baseline is. There's something right about this suspicion. As we mentioned above, the details of the counterexamples to purely probabilistic accounts of promotion do depend on the particular purely probabilistic account of promotion being targeted: such counterexamples exploit the purely probabilistic nature of those accounts together with the particular account's view of what the baseline is. For instance, returning to Schroeder's account of the baseline (viz., the agent's doing nothing), we can generate a counterexample by imagining a case where the agent's desire will be satisfied iff she in fact does nothing. In such a case, Schroeder's view will deliver the counterintuitive result that the agent's doing nothing does not promote her desire (despite guaranteeing it will be satisfied). This is because in this particular case the relevant action is identical to what Schroeder has chosen as the baseline; so, the satisfaction of the agent's desire is equally probable given the action as it is given the baseline. Structurally similar counterexamples arise for other purely probabilistic accounts. ${ }^{9}$ What these counterexamples have in common is that they are cases where, intuitively, an agent's action promotes her desire, and the agent thereby has reason to perform that action, but where the probability of the desire's satisfaction is incapable of rising, due to the details of the case, relative to the baseline. ${ }^{10}$

\subsection{Causal Probabilism}

In a recent article, Eden Lin has suggested that the availability of counterexamples to Pure Probabilism is rooted in those views' failure to require a causal connection between an agent's action and the uptick in probability sufficient for promotion. By contrast, then, Lin thinks an action promotes the satisfaction of a desire when (and only when) it makes or causes the probability of the desire's satisfaction to increase in the

\footnotetext{
${ }^{9}$ For an extended discussion of this counterexample to Schroeder's account, see Behrends and DiPaolo (2011, pp. 4) and Sharadin (2015, pp. 1373-5). For one targeting Coates's view, a version of which we'll discuss in more detail below (section 3.1), see Sharadin (2015) and Behrends and DiPaolo (2016).

${ }^{10}$ Some, for instance Lin (2016) and Fischer (2017), think that when one's desire is certain to be satisfied no matter what one does (e.g., in Debbie's case), nothing one can do promotes the satisfaction of that desire. Hence these philosophers think that purely probabilistic accounts are not subject to Debbie-style counterexamples. We think this intuition too firmly (indeed, in Fischer's case, explicitly) ties one's view about promotion to one's view about reasons. In any case, below we'll argue that probabilistic accounts face other difficulties too; so, for the sake of argument, we can admit that these counterexamples are not decisive.
} 
actual world, where the causal increase in probability is best understood as a change in probability over time -- from the time prior to the agent's action to a time after the action. "Hence Lin argues for what he calls "Simple Probabilistic Promotion," and what we'll call Causal Probabilism:

Causal Probabilism: For time $t_{1}$ prior to an agent A's $\varphi$-ing and later time $\mathrm{t}_{2}$ after A's $\varphi$-ing, $\varphi$-ing promotes the satisfaction of $\mathrm{D}$ iff $\varphi$-ing causes $\operatorname{pr}_{\mathrm{t} 2}\left(\right.$ satisfaction of D) $>\operatorname{pr}_{\mathrm{t} 1}($ satisfaction of $\mathrm{D}) .^{12,13}$

Lin's idea, then, is that promotion is a matter of causing something to be more likely than it was before: when an agent's action promotes the satisfaction of one of her desires, the action causes the desire to be more likely to be satisfied than it was prior to the action.

Just like Pure Probabilism, Causal Probabilism gets the right results in a range of cases: Why does buying a lottery ticket promote one's desire to have $\$ 100$ ? Because buying the lottery ticket causes the probability of having $\$ 100$ to be higher after buying the ticket than it was prior to buying it. Causal probabilism still has a potential problem with cases like Debbie, since the probability of Debbie's desire being satisfied was already 1 before she pressed the button. However, Lin (2016, p. 6-11) has argued that

${ }^{11}$ While Lin himself doesn't include one, we think it's natural to suppose that Lin's view should include a restriction on the relevant times prior to $\left(\mathrm{t}_{1}\right)$ and after $\left(\mathrm{t}_{2}\right)$ the agent's action. Such a restriction would, we think, naturally involve the existence of the desire at $\mathrm{t}_{1}$. To see why, suppose we do not require that $\mathrm{t}_{1}$ be a time when the agent's desire already exists -- or, if you think desires can be satisfied despite no longer existing, has already existed. Now suppose I do not now (at $\mathrm{t}_{1}$ ) desire a fig newton, but that, unless I'm informed of my serious allergy to figs, I will desire a fig newton in six days. Finally, suppose that, no matter what happens, I will be given a fig newton in seven days. Then it turns out that, given Causal Probabilism (without some restriction on $\mathrm{t}_{1}$ ), actions I might perform in the next several days that make it less likely that I'll be informed of my serious allergy to figs -- for instance, locking myself in a room -promote the satisfaction of my (future) desire for a fig newton. This is because such actions make it more likely that my desire for a fig newton will come into being (on day six), and hence subsequently be satisfied (on day seven). But, intuitively, what locking myself in my room causally affects is something about which desires I'll have, not which desires of mine are promoted. The counterintuitiveness of this result appears even greater if we invoke the standard connection between reasons and desire-promotion, since that would seem to imply that $\mathrm{I}$ have a reason, at $\mathrm{t}_{1}$, to lock myself in my room (since doing so would promote the satisfaction of my future desire). In any case, nothing in what follows depends on this issue. (Thanks to an anonymous referee for urging clarity on this point.)

${ }^{12}$ Lin (2016, p. 4). Here we precisify Lin's account slightly. Lin's official version is: S's doing A promotes $\mathrm{p}$ iff it makes $\mathrm{p}$ more likely to obtain than it was prior to the occurrence of A. Here we are focused on the case of desire promotion. We also make explicit that Lin's talk of "making more likely" should be understood in causal terms. In personal correspondence Lin has confirmed that the version of his account we give here is faithful to his intentions with respect to the account.

${ }^{13} \mathrm{Here}_{\mathrm{p}} \mathrm{pr}_{\mathrm{t} 1}(-)$ and $\mathrm{pr}_{\mathrm{t} 2}(-)$ are the relevant probability functions at $\mathrm{t}_{1}$ and $\mathrm{t}_{2}$ respectively. 
Debbie is not a genuine counterexample to Causal Probabilism, since the intuition that Debbie's desire is promoted is mistaken in his view. We will not critically discuss Lin's argument for that claim here; instead, we will argue that Causal Probabilism is subject to a range of other counterexamples. (We will shortly argue that the way to avoid these counterexamples is to go contrastive about promotion.)

Consider Bertie, who desires to run (and finish) a marathon. For simplicity, suppose that the following are the only relevant actions available to Bertie at $t_{1}$ :

Regular (R): Begin a regular training program

Sporadic (S): Begin a sporadic training program

No Training (N): Begin no training program

Since Bertie is conscientious, there's a good chance he'll engage in a regular training program, a much smaller chance he'll be sporadic in his training, and some non-negligible chance that he'll neglect his training altogether. Specifically, suppose that the following probabilities hold at $t_{1}$ with respect to Bertie's likelihood of embarking on these various training programs:

$$
\begin{aligned}
& \operatorname{pr}_{\mathrm{t} 1}(\mathrm{R})=.88 \\
& \operatorname{pr}_{\mathrm{t} 1}(\mathrm{~S})=.1 \\
& \operatorname{pr}_{\mathrm{t} 1}(\mathrm{~N})=.02
\end{aligned}
$$

Suppose further that the following conditional probabilities hold with respect to the chances of Bertie's finishing the marathon (F), given that he embarks on one of the training programs:

$$
\begin{aligned}
& \operatorname{pr}_{\mathrm{t} 1}(\mathrm{~F} \mid \mathrm{R})=.95 \\
& \operatorname{pr}_{\mathrm{t} 1}(\mathrm{~F} \mid \mathrm{S})=.2 \\
& \operatorname{pr}_{\mathrm{t} 1}(\mathrm{~F} \mid \mathrm{N})=.001
\end{aligned}
$$

These probabilities reflect the facts that runners who train regularly tend to finish marathons at a (much) higher rate than runners who train sporadically, and that those who train sporadically in turn tend to finish marathons at a (much) higher rather than those who don't train at all. Now consider what Causal Probabilism says about which of the actions available to Bertie at $t_{1}$ promotes his desire to finish a marathon. In order for Causal Probabilism to deliver a verdict, we need to know the probability, at $t_{1}$, that Bertie will finish the marathon, since it is only if that probability increases as a causal result of an action that that action promotes Bertie's desire. On the assumption that the 
courses of action listed above exhaust Bertie's options with regard to embarking on different training programs, we can calculate the probability of Bertie's finishing the marathon prior to beginning a training program (at $t_{1}$ ) as follows:

$$
\begin{aligned}
& \operatorname{pr}_{11}(\mathrm{~F})=\mathrm{pr}_{\mathrm{t} 1}(\mathrm{R}) * \mathrm{pr}_{\mathrm{t1}}(\mathrm{F} \mid \mathrm{R})+\mathrm{pr}_{\mathrm{t} 1}(\mathrm{~S}) * \mathrm{pr}_{\mathrm{t} 1}(\mathrm{~F} \mid \mathrm{S})+\mathrm{pr}_{\mathrm{t1}}(\mathrm{N}) * \mathrm{pr}_{\mathrm{t} 1}(\mathrm{~F} \mid \mathrm{N})=.88 * \\
& .95+.1 * .2+.02 * .001 \approx .856
\end{aligned}
$$

But then, according to Causal Probabilism, the only available action that Bertie could perform at $\mathrm{t}_{1}$ that would promote his desire to finish the marathon is to begin a regular training program (R). In particular, if Bertie engages in a sporadic training program (S), his probability of finishing the marathon will be equal to his prior conditional probability of finishing the marathon provided that he started a sporadic training program. That is:

$$
\mathrm{pr}_{\mathrm{t} 2}(\mathrm{~F})=\mathrm{pr}_{\mathrm{t} 1}(\mathrm{~F} \mid \mathrm{S})=.2
$$

Notice that Bertie's beginning a sporadic training program thus causes a decrease rather than an increase in the probability of his finishing the marathon. So Causal Probabilism entails that beginning a sporadic training program not only does not promote Bertie's desire, but in fact significantly dispromotes his desire. ${ }^{14}$

But this is a very awkward result! There is a clear sense in which Bertie's beginning a sporadic training program promotes his desire to finish a marathon -- and, correspondingly, a clear sense in which Bertie's desire gives him a reason to begin such a training program. Any adequate view of promotion should account for that. It is of course true that what would best promote Bertie's desire to finish -- and what Bertie's desire plausibly gives him most reason to do -- is to train regularly. He obviously has less reason to train sporadically, since this would less effectively promote his desire to finish the marathon. But it doesn't follow that he has no reason whatsoever to train sporadically, and, most importantly for our purposes here, it certainly doesn't follow that training sporadically would dispromote his desire to finish the marathon.

Bertie's case isn't isolated. Here's the recipe for generating other counterexamples: Take an agent who is antecedently very likely to perform one action that will make it very likely that her desire is satisfied (e.g., R), and who is antecedently very unlikely to do something that will make it somewhat less likely that her desire is satisfied (e.g., S). It will follow, according to Causal Probabilism, that only the thing the agent is

\footnotetext{
${ }^{14}$ Here, and in what follows, we use 'dispromote' as the opposite of 'promote.'
} 
antecedently very likely to perform (e.g., R) will promote the satisfaction of her desire, since only the action that makes it very likely that the desire is satisfied will generate the inequalities Causal Probabilism requires. However, in these cases, this is simply the wrong result. Although performing the antecedently likely action is what best promotes her desire in these cases, there is a clear sense in which other actions the agent might perform may also promote her desire (though not quite to the same degree). ${ }^{15}$

\subsection{Contrastive Probabilism}

So, like Pure Probabilism, Causal Probabilism appears to be subject to counterexamples. What to do? We think both sorts of counterexamples can be avoided by adopting a contrastive account of promotion -- one that mimics and complements a contrastive account of reasons such as Justin Snedegar's. ${ }^{16}$ Rather than taking promotion to be a non-contrastive affair, according to which an action either promotes, or fails to promote, the satisfaction of a desire simpliciter, we should take promotion to be a contrastive notion, according to which an action either promotes, or fails to promote, the satisfaction of a desire as compared to other actions. ${ }^{17}$ This basic idea can be spelled out in a probabilistic framework as follows:

Contrastive Pure Probabilism: Agent A's $\varphi$-ing rather than $\psi$-ing promotes desire D iff $\operatorname{pr}($ satisfaction of $\mathrm{D} \mid \mathrm{A} \varphi s)>\operatorname{pr}($ satisfaction of $\mathrm{D} \mid \mathrm{A}$ $\psi \mathrm{s}){ }^{18}$

\footnotetext{
${ }^{15}$ Lin appears to be aware that his view generates these sorts of results, and is aware that they appear problematic (see especially Lin 2016, pp. 18-19). Although he's aware of these problems, he doesn't offer a solution to them, saying instead that accepting Causal Probabilism would amount to "biting a bullet" (p. 19) on these points. Below, we offer a solution on his behalf (see footnote 18).
}

${ }^{16}$ Snedegar (2014). Here we follow Snedegar's proposal about how to understand the structure of contrastivism, though note that our interest in contrastivism concerns the promotion relation rather than the reason-for relation, which is that target of Snedegar's analysis. While we find Snedegar's proposal regarding contrastivism about reasons compelling, our account of promotion here is strictly speaking neutral on the nature of the reason-for relation. With that said, we do note that our contrastivism about promotion fits nicely into Snedegar's contrastivism about reasons, given a very modest assumption about how the two should be linked. Snedegar analyses what it takes for there to be a reason for an agent to $\varphi$ rather than $\psi$ in terms of whether $\varphi$-ing or $\psi$-ing better promotes one of the agent's desires. But what is it for $\varphi$-ing to promote a desire better than $\psi$-ing does? We submit that this is (at least extensionally equivalent to) its being the case that $\varphi$-ing rather than $\psi$-ing promotes the desire. If so, our account here in effect is an account of the promotion comparisons that Snedegar appeals to in his contrastivism about reasons.

${ }^{17}$ C.f. Snedegar (2014, esp. p. 52 and following).

${ }^{18}$ Causal Probabilism can also be given a contrastivist spin, roughly by contrasting how much two (or 
Note the two differences between Contrastive Pure Probabilism and its non-contrastive counterpart. First, an agent's action promotes the satisfaction of a desire only as contrasted with another action. ${ }^{19}$ Second, the baseline against which an agent's action is compared in terms of the probability of satisfying the desire is replaced with the contrasting action; hence, we now compare the probabilities of satisfying a desire given two different actions, as opposed to comparing the probabilities of satisfying that desire given an action and a baseline.

How does this modification to Pure Probabilism resolve the two problems discussed above? Let's start by examining Debbie's case, which seemed to cause problems for Finlay's account. The problem, in short, was the account's inability to say that Debbie's pressing A promotes her desire. But given a contrastive understanding of promotion, we are now in a position to identify the way in which Debbie's pressing A does promote her desire. Given the details of Debbie's case and Contrastive Pure Probabilism, we have the following:

(1) Debbie's pressing button A rather than $\mathrm{C}$ promotes the satisfaction of her desire.

(2) Debbie's pressing button B rather than C promotes the satisfaction of her desire.

(3) Debbie's pressing button A rather than B does not promote the satisfaction of her desire.

Given (1), there is a sense in which Debbie's pressing A promotes her desire, in that Debbie's pressing A rather than $C$ promotes the satisfaction of her desire. By the same

more) actions cause the probability of satisfying a desire to increase. Somewhat more precisely:

Contrastive Causal Probabilism: For time $t_{1}$ prior to an agent A's $\varphi$-ing or $\psi$-ing, and a later time $t_{2}$ after A's $\varphi$-ing or $\psi$-ing, $\varphi$-ing rather than $\psi$-ing promotes the satisfaction of D iff $\mathrm{I}_{\varphi}>\mathrm{I}_{\psi}$, where $I_{\varphi}$ is the increase in probability of satisfying $D$ between $t_{1}$ and $t_{2}$ that is (or would be) caused by $\varphi$-ing and $I_{\psi}$ is the increase in probability of satisfying $D$ between $t_{1}$ and $t_{2}$ that is (or would be) caused by $\psi$-ing.

However, it is worth noting that this account involves a comparison between different worlds (viz. worlds in which A $\varphi s$ and worlds in which A $\psi$ s), and thus arguably betrays Lin's (2016, pp. 4-5) central idea that promotion should only be based on a comparison of probabilities at different times in the same world. Partly for that reason, we will not be exploring the plausibility of Contrastive Causal Probabilism in what follows (though we invite others to do so).

${ }^{19}$ Or: set of multiple actions. Since this complication won't be important in the arguments to come, we ignore it in what follows. 
token, given (2), there is a sense in which Debbie's pressing B promotes her desire, in that Debbie's pressing B rather than $C$ promotes the satisfaction of her desire. Furthermore, it is intuitive that pressing $\mathrm{A}$ is just as good at promoting her desire as pressing $\mathrm{B}$ would be (since pressing either button satisfies her desire). That too is captured by Contrastive Pure Probabilism: (3) says that pressing A rather than $B$ doesn't promote the satisfaction of her desire. So, assuming as we are here some connection between promoting a desire and the existence of instrumental reasons, there is a reason for Debbie to press $\mathrm{A}$ rather than $\mathrm{C}$, a reason for her to press $\mathrm{B}$ rather than $\mathrm{C}$, but no reason to press $\mathrm{A}$ rather than $\mathrm{B} .^{20}$ And all of these claims seem like exactly the right results. ${ }^{21}$

Next recall Bertie's case, which constituted our counterexample to Causal Probabilism. The problem with Causal Probabilism was its inability to say that Bertie's embarking on a sporadic training program promotes his desire to finish a marathon. But given a contrastive understanding of promotion, we are now in a position to identify the way in which Bertie's sporadic training does promote his desire. Given the details of Bertie's case and Contrastive Pure Probabilism, we have the following:

(4) Bertie's sporadic training rather than no training promotes the satisfaction of his desire.

(5) Bertie's regular training rather than no training promotes the satisfaction of his desire.

(6) Bertie's sporadic training rather than regular training does not promote the satisfaction of his desire.

Given (4), there is a sense in which Bertie's sporadic training promotes his desire, in that Bertie's sporadic training rather than no training does promote the satisfaction of his desire to run a marathon. By the same token, given (5), there is a sense in which

\footnotetext{
${ }^{20}$ For more on contrastive reasons, see Snedegar (2014, esp. p. 53 and following; 2013).

${ }^{21}$ It is perhaps worth noting that Contrastive Pure Probabilism also entails the following about Debbie:
}

(3*) Debbie's pressing button A rather than not pressing button A does not promote the satisfaction of her desire.

This might initially seem like a puzzling or even counterintuitive result. However, this reaction is based on a confusion. Recall that it is stipulated in this case that Debbie would press button B if she does not press A. So, in this case, pressing B and not pressing A are just two different descriptions for the very same course of action. It follows, then, that there is no difference in this case between pressing A rather than $\mathrm{B}$, on the one hand, and pressing A rather than not pressing A, on the other hand. Thus (3) and (3*) stand and fall together. Since (3) is clearly true, the same goes for $(3 *)$. 
Bertie's regular training also promotes his desire, in that his training regularly rather than not at all certainly promotes his desire. Furthermore, it is intuitively plausible that Bertie's training sporadically rather than regularly does not promote the satisfaction of his desires, which is captured by (6). So, assuming as we are here the connection between promoting a desire and the existence of instrumental reasons, there's a reason for Bertie to train sporadically rather than not at all, regularly rather than not at all, and no reason to train sporadically rather than regularly. And again, all of these claims seem like exactly the right results. ${ }^{22}$

Before proceeding, it's worth briefly mentioning a complication, and an attendant possible worry. There certainly appear to be cases of promotion that are cases of promotion simpliciter, i.e., cases where an action promotes a desire not as contrasted to some other action's promoting that desire, but simply promotes the desire full stop. For instance, it's natural to say, as we said above, that buying a ticket to a fair lottery promotes an agent's desire to win (and to leave it at that). How can such apparently non-contrastive cases of promotion be analyzed within the contrastivist framework we are proposing?

Although there might be more than one plausible analysis on offer, we favor one along the following lines. Claims of promotion simpliciter are, we suggest, shorthand for contrastive promotion claims, where the contrasting action is determined by familiar conversational maxims. In particular, the contrasting action will be determined in part by Grice's maxim of quantity, which says to provide as much information is needed and no more. Accordingly, at least in ordinary conversational contexts, the conversationally salient contrasting action when one says that some action $\varphi$-ing promotes a desire (simpliciter) is simply the action of not performing the action in question, i.e., not- $\varphi$-ing. Hence in those contexts obeying the maxim of quantity would require making a promotion-simpliciter claim as opposed to a contrastive promotion claim, since it will be pragmatically determined that the contrasting action amounts to not performing the action. ${ }^{23}$

\footnotetext{
${ }^{22}$ There is a range of interesting features of contrastivism about promotion that we won't have the space to address here, e.g. how the contrast class is to be specified in a given case. Happily, the use to which we're putting contrastivism here doesn't depend on any particular answer to such questions. So, for reasons of space and ease of exposition, we put off discussion of them to another time, and, again, point the interested reader to Snedegar's $(2013,2014)$ work on how to deal with issues of this kind.

${ }^{23}$ Interestingly, this helps explain why the non-contrastive probabilistic accounts discussed above, such as Finlay's, take the baseline to be not- $\varphi$-ing. It helps explain, too, why there might be disagreement among probabilistic accounts over that baseline: Schroeder's account of the baseline (the agent's not doing anything at all) might be thought to be an alternative, equally good candidate for what is (sometimes, at least) a conversationally salient contrast class.
} 
So, we have shown how a simple contrastivist version of Pure Probabilism provides an elegant and intuitive way of dealing with well-known counterexamples to other purely probabilistic accounts, as well as our own counterexamples to Lin's more recent Causal Probabilism. Going forward, then, we're going to assume that the correct account of promotion will be a contrastive one, i.e., one that embraces the idea that actions promote -- or fail to promote -- the satisfaction of desires as contrasted with other possible actions. As we'll see in the next section, however, even a contrastive probabilistic account faces problems.

\section{Promotion as Involving Fit Between Desire and World}

In recent work, one of the authors of this present essay -- Nathaniel Sharadin (2015, 2016) -- has argued that all probabilistic accounts of promotion face a problem in accounting for certain cases of promotion. ${ }^{24}$ Sharadin's focus there is on non-contrastive purely probabilistic accounts of promotion. However, as we'll see, those arguments work against contrastive purely probabilistic accounts too. Since we've already argued that we have good reason to be interested in a contrastive probabilistic account of promotion (because such an account can avoid the counterexamples just adduced) here we'll focus our attention on showing how Sharadin's argument applies to contrastive probabilistic accounts of promotion. As we will see, Sharadin's argument motivates introducing the notion of fit between one's desire and the world as a central component in any account of promotion (including contrastive probabilistic accounts).

\subsection{Desires that Cannot Be Fully Satisfied}

Briefly, the problem Sharadin introduced is that it is sometimes possible to promote a desire but, given the desire's content, impossible to raise the probability of its satisfaction. For instance, consider one of his examples of a desire:

Extreme Ascetic (EA): The desire that none of your desires are satisfied. ${ }^{25}$

The probability of EA's satisfaction is always $0{ }^{26}$ But then, no matter what the relevant

\footnotetext{
${ }^{24}$ In what follows, although Sharadin is one of the authors of this present essay, we continue to refer to Sharadin in the third person, in order to avoid confusion between the previous and the present work.

${ }^{25}$ Sharadin (2016, p. 1).

${ }^{26}$ Either EA is satisfied, or EA is not satisfied. If EA is satisfied, then EA is not satisfied; if EA is not
} 
contrasting actions are supposed to be, Contrastive Pure Probabilism entails that it is impossible to promote EA. However, Sharadin argues that it is possible to promote EA. Suppose you have the desire EA and are offered the opportunity to frustrate the satisfaction of a large percentage of your desires - by taking a desire-frustration pill, say. Intuitively, you have a reason to take the pill rather than, say, to take a placebo. This, in turn, is because by taking the pill rather than the placebo you promote the satisfaction of your desire that none of your desires are satisfied (EA). After all, Sharadin reasons, fewer of your desires will be satisfied if you take the pill than if you take the placebo and you desire that none of your desires are satisfied. If fewer of your desires will be satisfied if you take the pill than if you take the placebo, then by taking the pill you'll in some sense move closer (though, of course, not all the way) to satisfying your desire that none of your desires are satisfied.. ${ }^{27}$ However, since you cannot move closer to satisfying EA probabilistically, Sharadin argues that we need to revise our account of promotion. ${ }^{28}$

Sharadin's argument has recently been criticized by Lin (2016). To explain Lin's objection, suppose Artie has an arbitrary set of desires S, among which is EA, and among which some subset $\mathrm{S}^{*}$ (not including EA!) is very likely to be satisfied in the course of the next week. Suppose also that Artie is offered a desire-frustration pill that will frustrate the satisfaction of all members of $\mathrm{S}^{*}$. Artie clearly has an (instrumental) reason to take the pill -- a point on which Lin and Sharadin agree. ${ }^{29}$ However, Lin disagrees with Sharadin's claim that the most natural explanation of this fact is that Artie's taking the pill will promote EA. Instead, Lin thinks that on the "most natural way of interpreting the case" Artie "has a number of related desires -- such as the desire to have fewer [of his] desires [satisfied]". ${ }^{30}$ In other words, Artie has something like:

EA*: The desire that as few of his desires as possible are satisfied.

According to Lin, it is EA*, not EA, that explains why Artie has a reason to take the satisfied, then EA is not satisfied. So, no matter what, EA is not satisfied. If some desire is not satisfied no matter what, then the probability that it is satisfied is (always) 0 .

${ }^{27}$ Sharadin (2015, p. 1380). DiPaolo and Behrends (2015) criticize this sort of "reason to promotion" inference. But see Sharadin (2016) for a reply.

${ }^{28}$ Note that Sharadin's worry is not just a worry for Contrastive Pure Probabilism. It's also a worry for Contrastive Causal Probabilism. Since, by hypothesis, the probability of EA cannot increase, nothing can, by hypothesis, be a cause of that probability increasing.

${ }^{29}$ C.f. Lin (2016, p. 16): "I agree that on the most natural way of filling in the details of the case, there is intuitively a reason for the agent" to take the pill.

${ }^{30} \operatorname{Lin}(2016$, p. 15). 
pill.

In a recent note, responding to the same point made by Jeffrey Behrends and Joshua DiPaolo, Sharadin offers a reply to this "neighboring desire" worry. ${ }^{31}$ In brief, Sharadin's claim is that the rationality of EA* is now in need of explanation, and the best explanation of why there is a reason for Artie have EA* is that doing so promotes EA: and then we're back off to the races. ${ }^{32}$ We lack the space to consider Sharadin's reply in detail here; but in any case, Lin goes further:

Suppose that, besides [EA], our agent truly has no other desires [such as EA*] whose satisfaction might be promoted by [taking the pill]. Moreover, suppose that our agent has some reason against [taking the pill] (e.g., it would [...] be mildly unpleasant). Intuitively, however weak this reason is, he has more reason against [taking the pill] than he does in favor of [taking it]. This can only be because he has no reason of any weight to [take the pill]. This means that [EA] does not give him a reason to [take the pill], and thus that [taking it] would not promote the satisfaction of this desire.

We reject Lin's intuitive judgment in this case as probative on three grounds. First: we do not find it intuitive that, supposing Artie really does have EA, that however weak some countervailing reason is, that reason will always outweigh the reason provided by EA. Indeed, any proponent of the idea that impossible desires can be promoted would plausibly have a countervailing intuition: given a sufficiently weak reason against taking the pill, the reason Artie has in favor of taking the pill will win out. Since Lin offers no argumentative support for the claim that it will always lose out (other than the report of his own intuition about the case) a proponent of the idea that impossible desires can be promoted has no reason to accept that the agent's reason against taking the pill is necessarily stronger than any reason provided by EA in favor of taking it.

Second: Lin's judgment about the case, if accurate, seems to itself deliver

\footnotetext{
${ }^{31}$ For DiPaolo and Behrends's argument see their (2015). For Sharadin's reply, see his (2016).

${ }^{32}$ Sharadin (2016, esp. p. 4 and following). As an anonymous referee points out, Sharadin's reply relies on two related contentious assumptions, viz. that (1) there must be a reason for the agent to have EA* and (2) the reason there is for the agent to have EA* is explained in the same way as the reasons there are for the agent to perform various actions. Again, we lack the space to adequately address these issues here; moreover, as we explain, even if we stipulate that there are no neighboring desires, there are issues with Lin's account.

${ }^{33} \operatorname{Lin}(2016$, p. 15-16).
} 
counterintuitive results. Suppose Artie has EA (and no further desire EA*) and is offered the choice between two pills, P1 and P2, one of which -- P1 -- will frustrate all the members of $\mathrm{S}^{*}$, and one of which -- P2 -- will frustrate all the members of $\mathrm{S}^{*}$ plus one other desire of his. Lin's judgment about this case will be that since there is no reason to take $\mathrm{P} 1$ and no reason to take $\mathrm{P} 2$, there is equal reason to take both. But we find this result bewildering. There is, intuitively, a stronger reason to take $\mathrm{P} 2$ than $\mathrm{P} 1$; and this, in turn, is because taking P2 better promotes EA. Of course, it doesn't better probabilistically promote EA (since it's impossible to probabilistically promote EA in any case). But that only blocks us from saying what it is natural to say about the case if we tie ourselves, as Lin's own account does, to a probabilistic understanding of promotion.

Third, and finally: Even if it were true, as Lin claims, that the agent always has more reason against taking the pill than in favor of taking it, this would not show, as Lin claims it does, that the agent has no reason of any weight in favor of taking the pill. For it could be that, as a result of the correct account of reasons' weights, reasons agents have for taking actions that would promote the desires they have that are impossible to satisfy are, as a matter of principle, always everywhere outweighed by the reasons agents have for taking actions that would promote the desires they have that it is possible to satisfy. Indeed, such an account of the weight of reasons has some attractive features: if it's truly impossible to satisfy a desire, then, intuitively, it should be the very last thing one tries to do among one's options, if one is trying to do what one has (most) reason to do. Since Lin doesn't offer us any reason for thinking such a view about the weight of reasons is somehow unacceptable or, more importantly, precluded by an alternative account of promotion, a proponent of the idea that impossible desires can provide reasons of some (perhaps lexically minimal) weight might well, for all Lin has said, accept such a view about the weight of reasons.

\subsection{The Disjunctive Alternative (in a Contrastivist Framework)}

Assuming, then, that we accept Sharadin's argument that desires such as EA can be promoted, what kind of account of promotion should we move towards? Sharadin's

\footnotetext{
${ }^{34}$ These two replies to Lin rely on competing intuitive judgments about cases. Of course, the usual caveats that apply to such arguments apply to this one: intuitions will vary, and readers are free to disagree with ours. But since Lin makes free use of his own intuitions in the argument, we think it's fair to appeal to our own -- and, importantly, to the intuitions of the proponent of the idea that desires it is impossible to satisfy can be promoted -- in reply.
} 
solution is to introduce the notion of fit between a desire and the world. In effect, the idea of fit is meant to flesh out what "moving closer" to the satisfaction of a desire amounts to, when it is not possible to do so probabilistically. Intuitively, fit between a world and a desire is a matter of match between the desire's content and the way the world is. According to Sharadin, we can formally model the intuitive idea of fit between a particular desire $D$ and the set of possible worlds $W$ by an order $\gtrsim_{\mathrm{D}}$ on $W$ so that, for some $D$ and for any two worlds $\mathrm{w}_{1}$ and $\mathrm{w}_{2}, \mathrm{w}_{1} \gtrsim_{\mathrm{D}} \mathrm{w}_{2}$ just in case $\mathrm{w}_{1}$ fits $\mathrm{D}$ at least as well as $\mathrm{w}_{2}$. We say that $\mathrm{w}_{1}$ is a strictly better fit for $\mathrm{D}$ than $\mathrm{w}_{2}, \mathrm{w}_{1}>_{\mathrm{D}} \mathrm{w}_{2}$, just in case $\mathrm{w}_{1} \gtrsim_{\mathrm{D}} \mathrm{w}_{2}$ but not $\mathrm{w}_{2} \gtrsim_{\mathrm{D}} \mathrm{w}_{1}$; and that $\mathrm{w}_{1}$ and $\mathrm{w}_{2}$ fit $\mathrm{d}$ equally well, $\mathrm{w}_{1} \sim_{\mathrm{D}} \mathrm{w}_{2}$, just in case $\mathrm{w}_{1} \gtrsim_{\mathrm{D}} \mathrm{w}_{2}$ and $\mathrm{w}_{2} \gtrsim_{\mathrm{D}} \mathrm{w}_{1}$.

With this model in hand, we can formulate a contrastivist version of Sharadin's sufficient condition for promotion. ${ }^{35}$ The most straightforward way of doing so contrasts the fit between desire and world in the closest possible worlds in which the agent performs the contrasted actions $\varphi$ and $\psi$ respectively. ${ }^{36}$ Thus, where $\mathrm{w}_{\varphi}$ stands for the (closest) world that would be realized were the agent to $\varphi$ and $\mathrm{w}_{\psi}$ stands for the (closest) world that would be realized were the agent to perform some contrasted action $\psi$, we have:

Contrastive Fit: Agent A's $\varphi$-ing rather than $\psi$-ing promotes the satisfaction of $\mathrm{D}$ if $\mathrm{w}_{\varphi}>_{\mathrm{D}} \mathrm{w}_{\psi}$.

Contrastive Fit yields the intuitively correct verdict in cases such as the one involving desire EA above. For notice that, on the plausible assumption that a world where less of your desires are satisfied $\left(\mathrm{w}_{\varphi}\right)$ exhibits a higher degree of fit with the desire to have none of your desires satisfied than the world where more of your desires are satisfied $\left(\mathrm{w}_{\psi}\right)$, taking the desire-frustration pill ( $\varphi$-ing) rather than taking the placebo ( $\psi$-ing) promotes the satisfaction of your desire to have none of your desires satisfied (EA).

But Contrastive Fit, if taken as a necessary condition on promotion as well as a sufficient condition, yields the incorrect results in cases like the simple lottery case. For notice that, on the plausible assumption that the closest world where you still have the

\footnotetext{
${ }^{35}$ I.e. a contrastivist modification of what Sharadin calls "Fit-Promote” (Sharadin 2015, p. 1381).

${ }^{36}$ This is the most straightforward way of doing it, but it is not entirely unproblematic. For notice that there might not be a single closest possible world in which the agent either $\varphi s$ or $\psi \mathrm{s}$. In that case, we would presumably have to compare the average fit of all the closest worlds in which the agent $\varphi s$ and $\psi \mathrm{s}$ respectively (when there is a single closest world, the average of the fit reduces to the fit, since the average of a single number is that number itself). Since this complication is irrelevant to our objections to the disjunctive alternative that is currently under consideration, and since the issue does not arise within our own account of promotion below, we will ignore it in what follows.
} 
\$1 you are considering spending on the lottery ticket exhibits a higher degree of fit with the desire to have $\$ 100$ than the closest world where you spend the $\$ 1$ on the lottery ticket (assuming this is not a world in which you turn out to win the lottery), buying the lottery ticket rather than not buying it dispromotes rather than promotes the satisfaction of your desire for $\$ 100$. In other words, you move farther away from the $\$ 100$ world in terms of fit while at the same time moving closer to the $\$ 100$ world in terms of probability.

Hence, according to Sharadin, the correct story about when an agent's action promotes her desire involves more than simply Contrastive Fit: the correct story is disjunctive. As we saw, just as there appear to be cases of promotion that do not involve an increase in probability, there appear to be cases of promotion that do not involve an increase in fit. Hence we must pair Contrastive Fit with a probabilistic account of promotion in order to get the disjunctive account of promotion Sharadin favors:

Contrastive Fit-Probabilism: An agent A's $\varphi$-ing rather than $\psi$-ing promotes D iff $\mathrm{w}_{\varphi}>_{\mathrm{d}} \mathrm{w}_{\psi}$ or $\operatorname{pr}($ satisfaction of $\mathrm{D} \mid \mathrm{A} \varphi \mathrm{s})>\operatorname{pr}($ satisfaction of $\mathrm{D} \mid \mathrm{A} \psi \mathrm{s})^{37}$

According to Sharadin, the disjunctive account represented by Contrastive Fit-Probabilism has "all the virtues" of a fit-based analysis (such as Contrastive Fit) "plus the virtues of a probabilistic analysis" such as those offered by contrastive pure probabilists (and, we can add, causal probabilists) while "avoiding the difficulties" faced by those accounts. ${ }^{38}$

While we think Contrastive Fit-Probabilism is superior to Contrastive Pure Probabilism (and other accounts discussed so far), it also faces serious problems. Having described two such problems in the next section, we'll proceed to offer a new account of promotion -- one that respects the motivations in favor of Contrastive Fit-Probabilism and yet solves our two problems with that view. In effect, then, the upshot will be twofold: Contrastive Fit-Probabilism is incorrect as it stands; but there's an attractive alternative proposal available that respects the motivations in favor of that view and improves on previously proposed accounts of promotion.

\footnotetext{
${ }^{37}$ Sharadin (2015, p. 1382). Although recall that Sharadin did not conceive of promotion in a contrastive manner in that paper.

${ }^{38}$ Sharadin (2015, pp. 1382-3).
} 


\section{Problems for Contrastive Fit-Probabilism}

Here we'll describe two problems for Contrastive Fit-Probabilism. The first problem we call the Degree Problem; it concerns the difficulties faced by Contrastive Fit-Probabilism in accounting for the fact that a desire can be promoted to a greater and lesser extent. The second problem we'll call the Problem of Mixed Cases; it concerns the difficulties faced by Contrastive Fit-Probabilism in accounting for cases in which probability increases but fit decreases, or, conversely, in which probability decreases but fit increases. 39

\subsection{The Degree Problem}

The Degree Problem is easiest to see by reminding ourselves of the connection there is supposed to be between an action's promoting a desire and there being a reason to perform that action. Recall that Humeans and non-Humeans disagree about whether instrumental reasons to perform an action, conceived as reasons agents have in virtue of facts about how an action promotes the agent's desires, exhaust all the reasons there are. Here we are not interested in arbitrating this dispute between the Humean and the non-Humean. Instead, we note that proponents of both views presumably think that the strength of the reason there is for an agent to perform an action, when that reason is grounded in facts about promoting the satisfaction of one of the agent's desires, depends in part on the degree to which that action promotes the relevant desire.

The upshot of this is that there are important theoretical reasons for Humeans and non-Humeans alike to think that promoting a desire is something that should be, at least in part, a matter of degree. However, Contrastive Fit-Probabilism provides a purely binary account of promoting a desire -- it offers no verdict at all about the degree to which a particular desire is promoted. To illustrate, notice that Contrastive Fit-Probabilism lacks the resources to distinguish between, on the one hand, a chocolate-desiring agent who is given a bar of chocolate rather than nothing at all, and, on the other hand, a chocolate-desiring agent who is given one out of 1 million tickets

\footnotetext{
39 Although we present these problems as targeted at Contrastive Fit-Probabilism it is worth noting that they apply with equal force to Sharadin's non-contrastive Fit-Probability Promote.

${ }^{40}$ But see Schroeder (2007, esp. Ch 7) for disagreement. Schroeder's rejection of this idea, what he calls "proportionalism" has not been widely adopted. For criticism, see Shackel (2013), Rieder (2016), and Evers (2013). For one recent attempt to articulate a proportionalist Humean view, see Manne (2016). Here, we assume some version of proportionalism is true.
} 
to a (fair) chocolate bar lottery rather than nothing at all. Contrastive Fit-Probabilism does deliver the result that both agents' desires are promoted. But, intuitively, there is an important distinction to be made in cases such as this between the (presumably lesser) degree to which receiving the lottery ticket promotes the agent's desire for a chocolate bar as compared to the (presumably higher) degree to which receiving the chocolate bar promotes that desire. An account of desire promotion that cannot draw such an intuitive and elementary distinction in cases such as these is severely impoverished.

One might object that this is not a special problem for Contrastive Fit-Probabilism since Contrastive Pure Probabilism is a binary account of promotion in precisely the same way. While this is strictly speaking true, Contrastive Pure Probabilism can easily be extended to account for degrees of promotion by claiming that an agent's $\varphi$-ing rather than $\psi$-ing promotes the satisfaction of a desire $\mathrm{D}$ to the extent that $\operatorname{pr}$ (satisfaction of $\mathrm{D} \mid \mathrm{A} \varphi s)$ is larger than $\operatorname{pr}($ satisfaction of $\mathrm{D} \mid \mathrm{A} \psi \mathrm{s})$. While there are many ways of spelling this out more precisely, the most straightforward approach simply exploits the difference between the two probabilities: ${ }^{41}$

Contrastive Pure Probabilism*: Agent A's $\varphi$-ing rather than $\psi$-ing promotes the satisfaction of desire $\mathrm{D}$ in proportion to [pr(satisfaction of $\mathrm{D} \mid \mathrm{A} \varphi s)-\operatorname{pr}($ satisfaction of $\mathrm{D} \mid \mathrm{A} \psi \mathrm{s})]$.

We are not endorsing this proposal to extend Contrastive Pure Probabilism into an account of degrees of promotion - indeed, we will present our own proposal below. However, this proposal illustrates how effortlessly any purely probabilistic account of promotion can be extended into an account of degrees of promotion, as any account of promotion arguably should be.

By contrast, it should be clear that due to the disjunctive nature of Contrastive Fit-Probabilism, no similar extension can be as effortlessly provided for that account. According to Contrastive Fit-Probabilism a desire can be promoted in two quite distinct ways, so an extension of the account to degrees of promotion would need to provide some way of weighting the contribution each way of promoting the desire makes to the degree of promotion. The problem here is not merely that Contrastive Fit-Probabilism is

${ }^{41}$ Other ways of spelling this out might exploit the ratio between pr(satisfaction of $\left.\mathrm{D} \mid \mathrm{A} \varphi \mathrm{s}\right)$ and $\operatorname{pr}($ satisfaction of $\mathrm{D} \mid \mathrm{A} \psi \mathrm{s})$, or the $\log$ of the ratio between these two probabilities. These ways of measuring the degree of promotion mirror some different Bayesian measures of incremental confirmation (see, e.g., Fitelson 1999). For a somewhat different proposal regarding degree of promotion, see Manne (2016). 
so far incomplete since no such weighting is provided by the account. The more serious problem is that Contrastive Fit-Probabilism fails to provide any guidance as to how we should choose between the infinitely many ways of providing such a weighting in a principled manner. This problem is exacerbated by the fact that it is highly doubtful that our intuitions will by themselves deliver anything close to reliable verdicts about which weightings accord better with our sense of what it is for a desire to be promoted to a greater or lesser extent.

\subsection{The Problem of Mixed Cases}

A related problem with disjunctive accounts of promotion such as Contrastive Fit-Probabilism concerns how such accounts deal with cases in which a desire is promoted along one dimension while being dispromoted along the other dimension. There are two types of cases that fall into this category of 'mixed' cases. In the first, the probability that a desire is satisfied increases while the fit between the desire and the world decreases. In the second, the probability that a desire is satisfied decreases while the fit between desire and the world increases. The problem for Contrastive Fit-Probabilism - indeed for any disjunctive account of promotion - is that it entails that the desire is necessarily promoted in any such case. This is an absurd consequence since we can let the decrease along one of the two promotion-dimensions be arbitrarily large and the increase along the other dimension be arbitrarily small. And in such cases, Contrastive Fit-Probabilism will nonetheless deliver the wildly counterintuitive result that the desire is promoted.

To see this clearly, consider one case of each type:

i. Annie desires to have 100 chocolate bars, and she currently has $49 .{ }^{42}$ She is offered the opportunity to trade all of her 49 bars for a ticket to the chocolate lottery, which pays the winner 100 chocolate bars. Since there are 100 tickets in the lottery, and since the lottery is a fair one with only one winner, her chance of winning would be $1 \%$. If we suppose Annie has no other prospects of obtaining 100 bars, then, since the probability of Annie's obtaining 100 chocolate bars would increase by her making the

\footnotetext{
${ }^{42}$ In this case, we could obviously have been more generous towards our protagonist, e.g. by giving her 99 chocolate bars rather than merely 49. However, we have chosen this particular number to get symmetry between the current example and the next one. In the next example, stipulating that our protagonist currently only has a $49 \%$ chance of winning the chocolate lottery preempts the response that Annie will win the chocolate lottery in the closest possible world in which Annie refuses the trade. (Thanks to an anonymous reviewer for raising this concern with the second example.)
} 
trade as compared with refusing to make the trade, Contrastive Fit-Probabilism entails that making the trade rather than refusing to do so would promote her desire for 100 chocolate bars. (For simplicity, we assume that Annie has no other means of acquiring chocolate bars.)

ii. Annie desires to have 100 chocolate bars, and she currently has 0 . However, Annie has 49 of the 100 tickets to the chocolate lottery, which pays the sole winner 100 bars, and so her current chance of obtaining 100 bars is $49 \%$. Annie is offered the opportunity to trade all of her lottery tickets for a single chocolate bar. Since the fit between Annie's desires and the world would thereby increase, Contrastive Fit-Probabilism entails that making the trade rather than refusing to do so would promote her desire for 100 chocolate bars. (Again we assume, for simplicity, that Annie cannot acquire chocolate in any other way.)

In each case, we submit that Contrastive Fit-Probabilism clearly delivers the wrong verdict. In the first case, it would not promote Annie's desire for 100 chocolate bars were she to give up her 49 bars for a $1 \%$ chance at 100 bars as compared to keeping the 49 bars. In the second case, it would not promote Annie's desire for 100 chocolate bars were she to give up her $49 \%$ chance at 100 bars for 1 bar as compared to keeping her $49 \%$ chance at 100 bars. We thus conclude that Contrastive Fit-Probabilism, at least in its current form, is flawed.

\section{A Unified Alternative Account}

We have just argued against Contrastive Fit-Probabilism on the basis of two problems the Degree Problem and the Problem of Mixed Cases - both of which exploit the disjunctive nature of the account. Yet we believe that Contrastive Fit-Probabilism is fundamentally correct in holding that there are two distinct ways for a desire to be promoted, i.e. by increasing the probability of its being satisfied and by increasing fit between the world and the desire. What we want, then, is a unified, i.e., non-disjunctive, account of promotion that accommodates both ways in which a desire can be promoted. In this section we present such an account (5.1) and show how it accommodates the virtues of Contrastive Fit-Probabilism (5.2) while avoiding the difficulties faced by that account (5.3).

\subsection{Contrastive Expected Fit}


We start by constructing a notion of expected fit analogous to the standard decision-theoretic notion of expected utility, essentially just replacing an agent's utility in a given outcome with the fit between the desire in question and the worlds in which the outcome holds. In this context, an outcome can be defined as a set of possible worlds with equal fit with respect to the desire in question (i.e. a set of possible worlds $\mathrm{W}$ such that $\mathrm{w}_{\mathrm{i}} \sim_{\mathrm{D}} \mathrm{w}_{\mathrm{j}}$ for all $\mathrm{w}_{\mathrm{i}}, \mathrm{w}_{\mathrm{j}}$ in $\mathrm{W}$, where $\mathrm{D}$ is the relevant desire. ${ }^{43}$ To define a notion of expected fit, we also need a numerical measure of how well the worlds in a given outcome fit the desire relative to complete frustration and satisfaction of that desire. So, we construct a function $F\left(o_{i}, D\right)$ from a outcome $o_{i}$ and a desire $D$ to a number on the unit interval $[0,1]$ such that an outcome that completely frustrates a desire maps onto 0 ; an outcome that completely satisfies the desire maps onto 1 ; and any pair of outcomes for which the worlds in the first outcome have a strictly better fit than the worlds in the second outcome is such that the first outcome maps onto a higher value on the unit interval than the second. Intuitively, this function can be thought of as measuring how large a proportion of a desire is satisfied in a given world, on a scale from 0 to 1 . With this function in hand, we define the expected fit of an agent A's action $\varphi$ relative to some desire D as the weighted sum of the fit between D and the world in each possible outcome, where each weight is given by the probability of the agent's obtaining the relevant outcome. More formally:

$$
\mathrm{EF}(\mathrm{A} \varphi \mathrm{s}, \mathrm{D})=\sum_{o_{i} \in O} \operatorname{pr}\left(\mathrm{o}_{\mathrm{i}} \mid \mathrm{A} \varphi s\right) \mathrm{F}\left(\mathrm{o}_{\mathrm{i}}, \mathrm{D}\right)
$$

where $\operatorname{EF}(\mathrm{A} \varphi s, \mathrm{D})$ is the expected fit of a desire $\mathrm{D}$ given that A performs an action $\varphi$, $\operatorname{pr}\left(\mathrm{o}_{\mathrm{i}} \mid \mathrm{A} \varphi s\right)$ is the probability of outcome $\mathrm{o}_{\mathrm{i}}$ given that $\mathrm{A} \varphi s, F\left(\mathrm{o}_{i}, \mathrm{D}\right)$ is the aforementioned measure of fit between $\mathrm{D}$ and and the world in $\mathrm{o}_{\mathrm{i}}$, and $\mathrm{O}$ is a partition of all possible outcomes of A's $\varphi$-ing. ${ }^{44}$

\footnotetext{
${ }^{43}$ Since an outcome is just a set of possible world with equal fit with respect to some desire, we will henceforth talk about fit between the desire and an outcome as a less cumbersome way of referring to the fit between the desire and each of the worlds in the outcome.
}

${ }^{44}$ Readers familiar with the distinction between Evidential Decision Theory (EDT) and Causal Decision Theory (CDT) will notice that our definition of expected fit corresponds more closely to the 'evidential' definition of expected utility than the competing 'causal' definition. However, a definition of expected fit that corresponds to the latter can easily be provided by simply replacing the conditional probability $\operatorname{pr}\left(\mathrm{o}_{\mathrm{i}} \mid \mathrm{A} \varphi \mathrm{s}\right)$ with the counterfactual probability that if A were to $\varphi, \mathrm{o}_{\mathrm{i}}$ would obtain, $\operatorname{pr}\left(\mathrm{A} \varphi \mathrm{s}>\mathrm{o}_{\mathrm{i}}\right)$. Presumably, a choice between these two slightly different ways of defining expected fit will be made on the basis of the same kind of considerations that are appealed to in the choice between EDT and CDT, including notably one's reaction to the infamous Newcomb's Problem -- 'one boxers' will use the definition of expected fit given the main text, while 'two boxers' will want to modify the definition in the way we have suggested here. Here we do not wish to take an official stand on this issue, but we will for 
Our account of promotion then simply says that a desire is promoted when the expected fit for the desire in question given that the agent performs the action in question is greater than the expected fit of the desire given the contrasting action. More precisely:

Contrastive Expected Fit: An agent A's $\varphi$-ing rather than $\psi$-ing promotes $\mathrm{D}$ iff $\mathrm{EF}(\mathrm{A} \varphi s, \mathrm{D})>\mathrm{EF}(\mathrm{A} \psi \mathrm{s}, \mathrm{D})$.

Why contrastive expected fit? That is, why not say that an agent's action promotes a desire when it increases the expected fit for her desire relative to some baseline (rather than as contrasted with some alternative action). Briefly, the answer is that although it's possible to construct a non-contrastive account of promotion around the notion of expected fit, such an account will face exactly the same sorts of trouble faced by non-contrastive probabilistic accounts of promotion such as those canvassed above. ${ }^{45}$ Hence here, and in what follows, we work with a contrastive version of the view. ${ }^{46}$

\subsection{Accommodating the Virtues of Contrastive Fit-Probabilism}

Contrastive Expected Fit accounts for the considerations that favor Contrastive Fit-Probabilism because it incorporates both considerations of fit and considerations of increased probability into a single measure. To see this clearly, consider first the following example: Bart has a desire $\mathrm{D}_{100 \text {-bars }}$ to have 100 chocolate bars, but has only $\$ 1$ to spend on chocolate. Each chocolate bar costs $\$ 1$, and Bart could therefore buy a single bar. (We assume, for simplicity, that there is no other way for Bart to obtain chocolate with his \$1.) According to Contrastive Fit-Probabilism, Bart would promote his desire by purchasing one chocolate bar rather than, say, purchasing nothing, since the fit for $\mathrm{D}_{100 \text {-bars }}$ in an outcome where Bart has one chocolate bar is clearly greater than

simplicity operate with the 'evidentialist' definition given in the main text in our discussion of examples below.

${ }^{45}$ For example, consider an account on which promotion consists in causing an uptick in expected fit -- a view analogous to Lin's Causal Probabilism, with probability of satisfaction replaced by expected fit. Although we did not specify the details about the degrees of fit of different outcomes in the original Bertie case, it is not hard to see that a version of the case can be constructed in which Bertie's beginning a sporadic training program would decrease the expected fit of his desire. Roughly, we need only assume that Bertie's expected fit for this desire was very high to begin with, due to his being very likely to begin a regular training program and there being a high degree of fit for the most probable outcomes of beginning such a training program.

${ }^{46}$ For more on this, see the discussion at the end of section 2. 
the fit in an outcome where Bart has no chocolate bar.

We agree with this verdict and thus hope to reproduce it in our own account, so consider the situation from the perspective of expected fit. If Bart buys a chocolate bar he will, with probability 1 , end up with an outcome in which he has one chocolate bar, and hence the expected fit will simply be the actual fit in that outcome. That is, since $\mathrm{P}\left(\mathrm{o}_{1 \text {-bar }}\right.$ Bart buys 1 bar $)=1$, we have $\mathrm{EF}\left(\right.$ Bart buys 1 bar, $\left.\mathrm{D}_{100 \text {-bars }}\right)=\mathrm{F}\left(\mathrm{o}_{1 \text {-bar }}, \mathrm{D}_{100 \text {-bars }}\right)$. By the same token, if Bart purchases nothing with his $\$ 1$, he will, with probability 1 , end up having zero chocolate bars, so the expected fit will simply be the actual fit in that outcome. That is, since $\mathrm{P}\left(\mathrm{o}_{0 \text {-bar }} \mid\right.$ Bart buys nothing $)=1$, we have $\mathrm{EF}$ (Bart buys nothing, $\left.\mathrm{D}_{100 \text {-bars }}\right)=\mathrm{F}\left(\mathrm{o}_{0 \text {-bars }}, \mathrm{D}_{100 \text {-bars }}\right)$. Since the fit in a 1-bar outcome is clearly greater than the fit in the 0-bar outcome Bart would end up in if he bought nothing, $\mathrm{F}\left(\mathrm{o}_{1 \text {-bar }}, \mathrm{D}_{100 \text {-bars }}\right)$ is clearly greater than $\mathrm{F}\left(\mathrm{o}_{0 \text {-bars }}, \mathrm{D}_{100 \text {-bars }}\right)$. So $\varphi$-ing promotes $\mathrm{D}_{100 \text {-bars }}$ according to Contrastive Expected Fit, as desired.

Consider next a modification of this case in which Bart is contemplating buying a ticket to a fair 100-ticket chocolate lottery, which conveniently pays the winner 100 chocolate bars and would thus satisfy Bart's desire for 100 chocolate bars $\left(\mathrm{D}_{100 \text {-bars }}\right)$. (Again we assume for simplicity that there is no other way for Bart to obtain chocolate with his \$1.) According to Contrastive Fit-Probabilism, Bart would promote his desire by purchasing a ticket rather than, say, purchasing nothing, since the probability of satisfying $\mathrm{D}_{100 \text {-bars }}$ is clearly greater if he purchases the ticket than if he does not.

Again we agree with this verdict and hope to reproduce it in our own account, so consider the expected fit of each course of action. If Bart buys the chocolate lottery ticket, the probability is $1 / 100$ that he will end up with perfect fit between $\mathrm{D}_{100 \text {-bars }}$ and the outcome (i.e., that he will end up with a fully satisfied desire $D_{100-\text { bars }}$ ) and 99/100 that he will end up with no fit between $\mathrm{D}_{100 \text {-bars }}$ and the outcome. Thus,

$$
\mathrm{EF}\left(\text { Bart buys ticket, } \mathrm{D}_{100 \text {-bars }}\right)=0.01 \times \mathrm{F}\left(\mathrm{o}_{100 \text {-bars }}, \mathrm{D}_{100 \text {-bars }}\right)+0.99 \times \mathrm{F}\left(\mathrm{o}_{0 \text {-bars }}, \mathrm{D}_{100 \text {-bars }}\right) \text {. }
$$

Contrast this with the expected fit of Bart purchasing nothing. In that case, Bart is certain to end up with an outcome in which he has zero chocolate bars, so the expected fit will simply be the actual fit in a zero-bar outcome. That is, since $\mathrm{P}\left(\mathrm{o}_{0 \text {-bar }} \mid\right.$ Bart buys nothing $)=1$, we have $\mathrm{EF}\left(\right.$ Bart buys nothing, $\left.\mathrm{D}_{100 \text {-bars }}\right)=\mathrm{F}\left(\mathrm{o}_{0 \text {-bars }}, \mathrm{D}_{100 \text {-bars }}\right)$. Given that $\mathrm{F}\left(\mathrm{o}_{100 \text {-bars }}, \mathrm{D}_{100-\text {-ars }}\right)$ is clearly greater than $\mathrm{F}\left(\mathrm{o}_{0 \text {-bars }}, \mathrm{D}_{100 \text {-bars }}\right)$, it follows that:

$$
\mathrm{EF}\left(\text { Bart buys ticket, } \mathrm{D}_{100 \text {-bars }}\right)>\mathrm{EF}\left(\text { Bart buys nothing, } \mathrm{D}_{100-\text {-bars }}\right) \text {. }
$$


So Bart buying the ticket rather than nothing promotes $\mathrm{D}_{100 \text {-bars }}$ according to Contrastive Expected Fit, as desired.

\subsection{Improving on Contrastive Fit-Probabilism}

We've just seen that Contrastive Expected Fit has the same advantages as Contrastive Fit-Probabilism. Recall, above, that we argued Contrastive Fit-Probabilism faced two problems: the Degree Problem and the Problem of Mixed Cases. In this section we'll explain how Contrastive Expected Fit solves both these problems and hence should be preferred over Contrastive Fit-Probabilism. Let us consider each problem in turn.

The Degree Problem for Contrastive Fit-Probabilism arose because of its disjunctive nature: unlike purely probabilistic accounts of promotion, there was no natural way of extending the account to make sense of the degree of promotion. The problem, as we saw, was not just that Contrastive Fit-Probabilism as it stands provides no way of weighting the two (disjunctive) ways in which a desire can be promoted; the more serious problem was that, given that there are infinitely many ways of providing such a weighting, and given that it's completely implausible to suppose that our intuitions can be trusted to deliver reliable, precise verdicts regarding which method of weighting is superior to all others, Contrastive Fit-Probabilism appears to be at a loss for how to proceed.

By contrast, Contrastive Expected Fit, like purely probabilistic accounts of promotion, can easily be extended to provide a natural account of the degree of promotion. Indeed, such an extension can be modelled on our earlier suggestion for how purely probabilistic accounts might be extended in this way:

Contrastive Expected Fit*: Agent A's $\varphi$-ing rather than $\psi$-ing promotes the satisfaction of desire $\mathrm{D}$ in proportion to $[\mathrm{EF}(\mathrm{A} \varphi \mathrm{s}, \mathrm{D})-\mathrm{EF}(\mathrm{A} \psi \mathrm{s}, \mathrm{D})]$.

In other words, the degree to which an agent's action promotes her desire by doing one thing rather than another is a function of how much greater the expected fit would be if one did the first thing as compared with the second. ${ }^{47}$ This provides for a simple and

${ }^{47}$ To see this proposal in action, consider a version of Bart's case where he is offered the chance to to buy 10 chocolate bars at the greatly discounted price of $\$ 1$. Intuitively, doing this this rather than buying nothing should promote his desire $\mathrm{D}_{100 \text {-bars }}$ to a much greater extent than buying only 1 bar at the original price of $\$ 1$ rather than buying nothing. This result is easily obtained: Since the fit between Bart's desire and the outcome is clearly greater when Bart has 10 bars rather than merely 1 , we have that

$$
\mathrm{F}\left(\mathrm{o}_{10 \text {-bars }}, \mathrm{D}_{100 \text {-bars }}\right)>\mathrm{F}\left(\mathrm{o}_{1 \text {-bar }}, \mathrm{D}_{100 \text {-bars }}\right) \text {. }
$$


intuitive way of measuring the degree of promotion while at the same time taking the fit into account. ${ }^{48}$

The second problem with Fit-Probabilism was that it delivered the wrong verdicts on what we called mixed cases, i.e., cases either where a single action increased the degree of fit between a desire and the outcome while simultaneously decreasing the probability of that desire's satisfaction or vice versa. To see how Contrastive Expected Fit solves this problem, consider the two variations on Annie's case again (4.2 above).

In both variations Annie, like Bart, desires to have 100 chocolate bars. In the first variation, Annie is offered the opportunity to trade the 49 chocolate bars she currently has for a $1 \%$ chance at winning 100 bars. Contrastive Fit-Probabilism says that, because the probability of Annie satisfying her desire for 100 bars goes up were she to trade her 49 bars rather than reject the trade, doing so promotes her desire. In the second variation, Annie is offered the opportunity to trade the 49 out of 100 tickets to the 100 chocolate bar lottery she currently has for a single chocolate bar. Contrastive Fit-Probabilism says that, because the fit between Annie's desire and the outcome goes up were she to trade her tickets for the single chocolate bar, accepting rather than rejecting the trade promotes her desire. Both results are, as we said, incorrect. Intuitively, in the first variation Annie's desire is not promoted by trading her bars for the single ticket. And in the second variation, Annie's desire is not promoted by trading her tickets for the single bar.

Let us consider how Contrastive Expected Fit deals with these cases. In the first variation of the case, refusing to make the trade guarantees that Annie will continue to have 49 chocolate bars. Thus the expected fit for refusing the trade is simply:

$$
\mathrm{EF}\left(\text { Annie refuses } 1 \text { st trade, } \mathrm{D}_{100 \text {-bars }}\right)=\mathrm{F}\left(\mathrm{o}_{49-\text {-bars }} \mid \mathrm{D}_{100 \text {-bars }}\right) \text {. }
$$

As before (see section 5.2), we have that $\mathrm{EF}\left(\right.$ Bart buys 1 bar, $\left.\mathrm{D}_{100 \text {-bars }}\right)=\mathrm{F}\left(\mathrm{o}_{1 \text {-bar }}, \mathrm{D}_{100 \text {-bars }}\right)$. By the same reasoning, $\mathrm{EF}\left(\right.$ Bart buys 10 bars, $\left.\mathrm{D}_{100 \text {-bars }}\right)=\mathrm{F}\left(\mathrm{o}_{10 \text {-bars }}, \mathrm{D}_{100 \text {-bars }}\right)$. We thus get:

$\mathrm{EF}\left(\right.$ Bart buys 10 bars, $\left.\mathrm{D}_{100 \text {-bars }}\right)>\mathrm{EF}\left(\right.$ Bart buys 1 bar, $\left.\mathrm{D}_{100 \text {-bars }}\right)$

We now subtract by $\mathrm{EF}$ (Bart buys nothing, $\mathrm{D}_{100 \text {-bars }}$ ) on both sides of the inequality to obtain

$\mathrm{EF}$ (Bart buys 10 bars, $\left.\mathrm{D}_{100 \text {-bars }}\right)-\mathrm{EF}\left(\right.$ Bart buys nothing, $\left.\mathrm{D}_{100 \text {-bars }}\right)$

as desired.

$>\mathrm{EF}\left(\right.$ Bart buys 1 bar, $\left.\mathrm{D}_{100 \text {-bars }}\right)-\mathrm{EF}\left(\right.$ Bart buys nothing, $\left.\mathrm{D}_{100 \text {-bars }}\right)$

${ }^{48}$ Again, as in the case of probabilistic accounts, there are other possible ways of spelling out the degree of promotion that exploit the ratio between the two expected fits, or perhaps the log of the ratio between these two values. Here we don't take a stand on whether one of these is preferable to the others, since we don't yet see any theoretical reason to prefer one to the others. We think investigating the question of whether there are reasons to opt for one or the other measure would be worth pursuing, but it's not something we have the space to do here. 
By contrast, the expected fit for making the trade is:

$$
\begin{aligned}
& \mathrm{EF}\left(\text { Annie makes 1st trade, } \mathrm{D}_{100 \text {-bars }}\right)=0.01 \times \mathrm{F}\left(\mathrm{o}_{100 \text {-bars }}, \mathrm{D}_{100 \text {-bars }}\right)+0.99 \mathrm{x} \\
& \mathrm{F}\left(\mathrm{o}_{0 \text {-bars }}, \mathrm{D}_{100 \text {-bars }}\right) \text {. }
\end{aligned}
$$

Now, of course, the expected fit for each action will depend on how well Annie's desire for 100 chocolate bars fits the three outcomes at play here, i.e. $\mathrm{o}_{0 \text {-bars }}, \mathrm{o}_{49 \text {-bars }}$, and $\mathrm{o}_{100 \text {-bars }}$. However, it is clear that any plausible measure of fit -- i.e. any plausible function F -will result in a higher expected fit for refusing the trade than for making it. To see this, note that $\mathrm{D}_{100 \text {-bars }}$ is fully unsatisfied in $\mathrm{o}_{0 \text {-bars }}$-- it could not possibly have a lesser fit -and so, whatever else is true of our measure of fit, it will assign a value of zero to $\mathrm{F}\left(\mathrm{o}_{0 \text {-bars }}, \mathrm{D}_{100 \text {-bars }}\right)$. It follows from this minimal assumption that $\mathrm{EF}$ (Annie refuses $1 \mathrm{st}$ trade, $\left.\mathrm{D}_{100 \text {-bars }}\right)$ is larger than $\mathrm{EF}\left(\right.$ Annie makes 1 st trade, $\mathrm{D}_{100 \text {-bars }}$ ) if and only if

$$
\mathrm{F}\left(\mathrm{o}_{49-\text {-bars }} \mid \mathrm{D}_{100 \text {-bars }}\right)>0.01 \times \mathrm{F}\left(\mathrm{o}_{100 \text {-bars }}, \mathrm{D}_{100 \text {-bars }}\right) \text {. }
$$

This means that the fit for Annie's desire $\mathrm{D}_{100 \text {-bars }}$ would have to be at least 100 times less in an outcome in which she has 49 chocolate bars $\left(\mathrm{o}_{49-\text { bars }}\right)$ than in an outcome in which she has 100 bars $\left(\mathrm{o}_{100 \text {-bars }}\right)$ in order for Annie's desire to be promoted by making the trade rather than refusing it. Thus we get the intuitively correct result that Annie's measure of fit for $\mathrm{D}_{100 \text {-bars }}$ would have to exhibit a truly extreme preference for 100 bars as opposed to 49 in order for the desire to be promoted by making the trade rather than refusing it.

In putting the point this way, we assume that measures of fit are relative to agents. So, for instance, we assume that it's possible for two agents to have a desire with the same content, e.g., for 100 chocolate bars, for both agents to be in an outcome the content of which matches the content of that desire to the same degree, e.g., an outcome in which each agent has 49 chocolate bars, and yet for the fit between each agent's desire and the outcome to differ. We find this way of thinking of things attractive, as it allows for variation in how well outcomes match desires not just in terms of the explicit match between the content of an outcome and the content of a desire, but also between the content of an outcome and the non-contentful character of a desire, for instance, how important fully satisfying that desire is to the agent. Hence it allows, for instance, that our two agents might each want 100 chocolate bars, each have 49, but that one agent cares a great deal about getting those last 51 bars, and the other cares substantially less. (That is, in effect, what we just saw in Annie's case, above.) 
Importantly, however, this assumption isn't necessary to make the point. (Indeed, it's worth pointing out that Sharadin's (2015) description of the measure of fit between outcomes and desires leaves open whether he intends it to be agent-relative or non-agent-relative.) Suppose instead that measures of fit are not relative to agents, so that two agents symmetrically situated both in terms of the content of their desires and the content of the outcomes they are in are also always symmetrically situated in terms of the fit between their desires and the outcomes. Then, our argument amounts to an argument for a restriction on any plausible measure of (non-agent-relative) fit, viz., that increasing match in content sometimes generates diminishing (but plausibly non-zero) returns in terms of fit. Going forward, we'll continue to assume the agent-relative measure of fit, but note that the arguments can also be read in this alternative way.

In the second variation of Annie's case, refusing to make the trade guarantees that Annie will continue to have a $49 \%$ probability of having 100 chocolate bars. Thus the expected fit for refusing the trade is:

$$
\begin{aligned}
& \mathrm{EF}\left(\text { Annie refuses } 2 \text { nd trade, } \mathrm{D}_{100-\text { bars }}\right)=0.49 \times \mathrm{F}\left(\mathrm{o}_{100 \text {-bars }} \mid \mathrm{D}_{100 \text {-bars }}\right)+0.51 \times \\
& \mathrm{F}\left(\mathrm{o}_{0 \text {-bars }}, \mathrm{D}_{100 \text {-bars }}\right) \text {. }
\end{aligned}
$$

By contrast, making the trade guarantees Annie a single chocolate bar but also prevents her from getting any further chocolate bars. Thus the expected fit for making the trade in this variation of the case is simply:

$\mathrm{EF}\left(\right.$ Annie makes 2 nd trade, $\left.\mathrm{D}_{100 \text {-bars }}\right)=\mathrm{F}\left(\mathrm{o}_{1 \text {-bar }}, \mathrm{D}_{100 \text {-bars }}\right)$

Again, the expected fit for each action will depend on how well Annie's desire for 100 chocolate bars fits the three outcomes at play here, i.e. $\mathrm{o}_{0 \text {-bars }}, \mathrm{o}_{1 \text {-bar }}$, and $\mathrm{o}_{100 \text {-bars. }}$. By the same token as before, however, we have that $\mathrm{EF}\left(\right.$ Annie refuses 2 nd trade, $\mathrm{D}_{100 \text {-bars }}$ ) is larger than $\mathrm{EF}$ (Annie makes 2 nd trade, $\mathrm{D}_{100 \text {-bars }}$ ) if and only if

$$
0.49 \times \mathrm{F}\left(\mathrm{o}_{100 \text {-bars }} \mid \mathrm{D}_{100 \text {-bars }}\right)>\mathrm{F}\left(\mathrm{o}_{1 \text {-bar }}, \mathrm{D}_{100-\text {-bars }}\right) .
$$

This means that the fit for Annie's desire $\mathrm{D}_{100 \text {-bars }}$ in an outcome in which she only has a single bar would have to be roughly half (49\%) of that in which she has all 100 of the chocolate bars in order for Annie's desire to be promoted by making the trade rather than refusing it. So we again get the intuitively correct result that Annie's measure of fit for $\mathrm{D}_{100 \text {-bars }}$ would have to be extremely peculiar in order for the desire to be promoted by making the trade rather than refusing it. Of course, without specifying more about Annie, her measure of fit might still have such a structure, but its peculiarity explains 
why our intuitions balk at the suggestion that trading in all those lottery tickets for a single chocolate bar would promote her desires.

\section{What Kind of Probability?}

Before concluding, it's worth mentioning one final aspect of our account that might appear to be a lacuna at first glance, but we think is in fact an advantage of the view. Contrastive Expected Fit, like its competitors, appeals to probability in analyzing the promotion relation. In particular, it appeals to the probability that one action would result in a world that more closely fits an agent's desire than some contrasting action. But what kind of probability is being employed in this analysis? ${ }^{49}$ There are two plausible possibilities: either the kind of probabilities appealed to are objective chances, or they are subjective probabilities of some sort or other. Which do we endorse? Both.

To explain, we think that strictly speaking there are two equally good interpretations of Contrastive Expected Fit corresponding to the two kinds of probability. On the objective interpretation, the probabilities appealed to in Contrastive Expected Fit should be read as objective chances, and the view yields verdicts regarding what actions as a matter of fact promote what desires. That is, it yields objective truths about what actions stand in the promotion relation to what desires. On the subjective interpretation, the probabilities appealed to in Contrastive Expected Fit should be read as subjective probabilities, and the view yields verdicts regarding what actions promote what desires according to some subject. That is, it yields verdicts about what actions stand in the promotion relation to what desires in the opinion of that agent.

Why opt for a view of this sort? Recall from the introduction that the promotion relation is thought to have something to do with agents' reasons: for certain Humean views, all reasons are reasons in virtue of facts about promotion, and for non-Humeans, at least some reasons (intuitively the instrumental reasons) are reasons in virtue of facts about promotion. Now notice that there is a distinction among reasons that corresponds quite nicely to the two plausible interpretations of Contrastive Expected Fit, viz. the distinction between objective and subjective reasons, where the difference between these two kinds of reasons is understood as a difference between considerations that in fact count in favor of an action and considerations that, from the point of view of some subject, count in favor of an action. ${ }^{50}$ So, corresponding to the objective interpretation

\footnotetext{
49 This is a question faced by any account of promotion that appeals to probabilistic facts. See Behrends \& DiPaolo (2016) for a discussion.

${ }^{50}$ In the literature, the terms 'subjective reason' and 'objective reason' are used to refer to a range of differences among reasons. For instance, some use 'subjective reason' to refer to the subset of objective
} 
of Contrastive Expected Fit, we have what we might call the objective promotion relation that delivers results regarding objective reasons, understood as above. And similarly, corresponding to the subjective interpretation of Contrastive Expected Fit, we have what we might call the subjective promotion relation that delivers results regarding subjective reasons, again understood as above.

Now, there are serious disagreements among philosophers about which of these kinds of reasons corresponding to the different promotion relations are genuine normative reasons -- all views in logical space are occupied. Here, we don't take any stand on which of these views is correct. For all we say here, it could turn out that only objective reasons are genuine, and that subjective reasons aren't reasons at all. It could turn out, in other words, that the fact that from the point of view of some subject one action has a higher expected fit than an alternative action is neither here nor there with respect to what action there is reason for the subject to do. Anyone inclined toward such a view should then insist on the objective interpretation of Contrastive Expected Fit. (The reverse is true for those who think think there are only subjective reasons and no genuine objective reasons..) Since it's not our aim here to decide these difficult questions, we think it's an advantage of our view that it both remains silent on them and allows for a range of possible answers.

\section{Conclusion}

Let's recap. Probabilistic accounts of promotion -- Pure Probabilism and Causal Probabilism -- are liable to counterexamples that militate in favor of a contrastive understanding of promotion. Unfortunately, even going contrastive won't save those accounts: they're liable to their own set of counterexamples that exploit their purely probabilistic nature. Contrastive Fit-Probabilism solves the problems with those views, but its disjunctive nature makes it subject to its own problems: the Degree Problem and the Problem of Mixed Cases. Our alternative -- Contrastive Expected Fit -- represents a unified, non-disjunctive alternative that solves these problems.

Where does this leave us? Our account of promotion, if correct, reveals that the theory of what it is for an action to promote a desire appeals to a notion of expected fit which is interestingly analogous to the decision-theoretic notion of expected utility employed in

reasons to which an agent has epistemic access, so that something cannot be a subjective reason without also being an objective reason. By contrast, our use of the terms here allows for this possibility. We don't care to die on this particular terminological hill. Instead, we're interested in highlighting the parallel between these two senses of a reason -- whatever, in the end, it's correct to call them -- and the two possible interpretations of Contrastive Expected Fit. 
expected utility theory. On reflection, we think this structural similarity shouldn't be too surprising. After all, expected utility theory can naturally be described as an account of rational action according to which actions should be compared with regard to how well they promote overall utility. A similarly sophisticated account of promoting desires thus plausibly employs the same formal machinery for explicating the notion of promoting a desire. Indeed, looking ahead, it's worth exploring whether there are other fruitful connections between these two areas. More generally, there are a number of interesting issues we haven't addressed here that are worthy of attention, e.g. about whether the correct measure of fit is agent-relative or non-agent-relative, about how to spell out a gradable notion of promotion (see footnotes 40 and 46), about whether expected fit should be given an 'evidential' or 'causal' definition (see footnote 43), and, of course, on the correct view to take about the connection between promotion and reasons. We leave these issues to another time.

\section{References}

Behrends, J., \& DiPaolo, J. (2011). "Finlay and Schroeder on Promoting a Desire," Journal of Ethics \& Social Philosophy, 6: 1-6.

Behrends, J., \& DiPaolo, J. (2016). "Probabilistic Promotion Revisited," Philosophical Studies 173: 1735-1754.

Coates, D. J. (2014) “An Actual Sequence Theory of Promotion," Journal of Ethics \& Social Philosophy: 1-7.

DiPaolo, J. and Behrends, J. (2015) "Reason to Promotion Inferences," Journal of Ethics \& Social Philosophy: 1-9.

Evers, D. (2013). “In Defence of Proportionalism," European Journal of Philosophy 21 (2): 313-320.

Finlay, S. (2006). "The Reasons That Matter," Australasian Journal of Philosophy, 84 (1): $1-20$.

Finlay, S. (2010). "What 'ought' probably means, and why you can't detach it," Synthese, 177 (1): 67-89.

Finlay, S. (2014). Confusion of Tongues: A Theory of Normative Language. Oxford: Oxford University Press.

Fischer, S. (2017). “On Promoting the Dead Certain: A Reply to Behrends, DiPaolo and 
Sharadin," Journal of Ethics and Social Philosophy: 1-12.

Fitelson, B. (1999). "The Plurality of Bayesian Measures of Confirmation and the Problem of Measure Sensitivity," Philosophy of Science 66: S362-S378.

Hitchcock, C. (2004). "Do all and only causes raise the probabilities of effects?" In J. Collins, N. Hall, \& L. A. Paul (Eds.), Causation and Counterfactuals. Cambridge, MA: MIT Press.

Hubin, D. (1999). “What's Special about Humeanism,” Noûs 33 (1): 30-45.

Kolodny, N. (forthcoming). "Instrumental Reasons," in The Oxford Handbook of Reasons and Normativity, ed. Daniel Star. Oxford: Oxford University Press.

Korsgaard, C. (1996). The Sources of Normativity. Cambridge: Cambridge University Press.

Lin, E. (2016). "Simple Probabilistic Promotion," Philosophy and Phenomenological Research, online first.

Maguire, B. (2016). “The Value-Based Theory of Reasons," Ergo 3 (9): 233-262.

Manne, K. (2016). “Democratizing Humeanism," in Weighing Reasons, eds. Errol Lord and Barry Maguire. Oxford: Oxford University Press.

Rieder, T.N. (2016). "Why I'm Still a Proportionalist," Philosophical Studies 173 (1): 251-270.

Scanlon, T. (2015). Being Realistic about Reasons. Oxford: Oxford University Press.

Schroeder, M. (2007). Slaves of the Passions. Oxford: Oxford University Press.

Shackel, N. (2014). "Still Waiting for Plausible Humean Theory of Reasons," Philosophical Studies 167: 607-633.

Sharadin, N. (2015) "Problems for Pure Probabilism about Promotion (and a Disjunctive Alternative)," Philosophical Studies 172 (5): 1371-86.

Sharadin, N. (2016) "Checking the Neighborhood: A Reply to DiPaolo and Behrends on Promotion," Journal of Ethics \& Social Philosophy: 1-8.

Snedegar, J. (2013). "Reasons Claims and Contrastivism about Reasons," Philosophical Studies, 166(2): 231-242.

Snedegar, J. (2014). “Contrastive Reasons and Promotion,” Ethics, 125(1): 39-63. 